\title{
5. Identity Confers Power: The New View of Leadership in Social Psychology ${ }^{1}$
}

\author{
John C. Turner, Katherine J. Reynolds and Emina Subasic
}

\section{Introduction}

In this chapter we examine the question 'what is leadership?' and how it is understood from the perspective of social psychology. This field traditionally has been very interested in the question of leadership, with Kurt Lewin being one of the first to describe and empirically investigate the workings of authoritarian, democratic, and laissez-faire leaders (Lewin, Lippett and White 1939). Despite an encouraging start, in the post-war period the leadership question tended to disappear in social psychology, shifting into organisational psychology and other fields. The topic was approached largely implicitly in the 'group dynamics' tradition and through the study of 'group processes' - most fundamentally, of 'social influence' (Turner 1991). At the end of the 1970s, however, a new theory of the psychological group emerged — self-categorisation theory (for example, Turner, Oakes, Haslam and McGarty 1994; Turner, Hogg, Oakes, Reicher and Wetherell 1997). Over the last 20 or so years, research on self-categorisation theory (SCT) has produced a new way of understanding leadership in social psychology (for example, Turner and Haslam 2001).

This theory not only provides an integrated view of leadership, it also, importantly, offers an analysis of the dynamics of leadership - the ways in which leadership is gained, maintained, challenged and contested. Self-categorisation theory provides a new view of leadership that can speak as much to how an individual person within a group comes to have influence as to the way particular groups, elites, institutions, and authorities within society shape the system as a whole. It has been applied, for example, to better understand when the influence of certain leaders is likely to wane and new leaders will emerge within groups. In the same way, it speaks to issues of intergroup relations and examines when certain groups within a system are likely to accept or reject the status-quo (for example, the emergence of social movements, mobilisation and challenge - see Simon and Klandermans 2001; also West, this volume). As such, this view has been applied in the organisational domain to explain organisational functioning, to international relations and managing conflict between groups (for example, between Protestants and Catholics in Northern Ireland) and to the political contests within nations. The 
focus here, though, given space, will be on explaining in a very brief form the basic principles of the approach.

\section{What is a social psychological perspective on leadership?}

Social psychology is a social science, but a peculiar one. We are speaking here of the social psychology which is a major branch of modern psychology (not the field in sociology). It is a science devoted to the study of underlying causality, strongly oriented to abstract basic processes and the laboratory experiment. It does not seek primarily to describe or understand social interaction, institutions, or societies in their concrete specificity, but tries to understand the nature of the human mind (a mental system not a directly social one) at work in social life. What does social life tell us about the mind, how does the mind make society and social interaction possible, and how is the mind affected by its relationship to social life? Moreover, historically, there has been controversy about how to approach such questions. Social identity and self-categorisation theorists have been most vocal in arguing that social psychology must acknowledge the functional interdependence of mind and society in its theorising about the nature of mental processes (for example, Turner and Oakes 1997). This view contrasts with more individualistic approaches that reduce the working of the mental system to general (individual) psychological properties (for example, information processing and memory systems) or the nature of the individual perceiver (for example, personality, biology, socialisation experiences).

These same tensions concerning the appropriate level of explanation for behaviour exist very clearly in the leadership domain. Researchers, including social psychologists, have looked in an eclectic fashion at just about everything they could think of to do with leadership. The explanations offered often depend implicitly or explicitly on underlying theories of human behaviour. They have tried to define who will be leaders and who will not, what leaders do, what functions they serve, how they differ from non-leaders and what kinds of leaders produce what kinds of results in what kinds of situation. There has also been an attempt to identify the different kinds of psychological processes at work in different kinds of leadership and this attempt takes us into the realm of social psychology proper.

The social psychological perspective seeks to understand (in terms of general, abstract theoretical principles) the processes that enable individuals and group members to influence each other and develop shared norms and values and places leadership within this context. It has tended, since the emergence of the group dynamics tradition, based on the work of Kurt Lewin and others, to think of leadership in terms of relative influence within a group and the leader(s) as the person, role or subgroup which exerts more influence over the group than others. This statement of the leadership-influence connection is a summary of a 
huge field with many complicated areas (for example, group polarisation, minority influence, crowd behaviour, conformity, persuasion, power etc.).

Putting things more descriptively, we could say that social psychologists assume that leaders are group members who: exert more influence than others; tend to be seen as more trustworthy, prestigious, valued, credible and fair; and who play the most important role in the group in terms of directing it towards its goals, holding the group together socially and emotionally, and inspiring and motivating members to work towards and live up to a collective vision anchored in a common identity. The key point, however, is that we seek to understand the causal processes which produce such outcomes and judgements. It may or may not be the case, for example, that a particular kind of leader or leadership style is more effective than another in some situation but, irrespective of whether leaders are, or turn out to be, effective or not, why do group members follow some people and not others in the first place? What are the processes which lead members to find a person or authority persuasive, credible, legitimate, likely to prove right, etc.?

\section{What have been the main ways in which leadership has been approached?}

The person-centred view like the common lay conception argues that leadership reflects the personal qualities of individuals. These may be traits, behaviours, or behavioural styles. The implication is that certain individuals who differ from others in terms of their personal qualities relatively consistently across situations and time will tend to become leaders no matter the group or circumstance. In some sense leadership is driven by the person, flowing from the person to the group. If one has not got what it takes one will not become a leader and, if one has, then one can impose it on others. The evidence for this popular view is arguable at best and probably non-existent (for example, Mann 1959; also see Turner and Haslam 2001, and Haslam 2004 for more detailed overviews of approaches to leadership).

The contingency view also assumes that leaders have specific kinds of qualities but holds that these qualities will produce actual or effective leadership only in the right kinds of situation (for example, Fiedler 1964). Interpreted loosely this is fine, but the direction of work has focused on the stable individual qualities of the leader and defining situational features in a very static mechanic way (for example, group relations, high level of structure, and formal position of authority). There is no sense that a leader needs to be sensitive to the norms of a particular group and adapt to reflect these as the needs, interests and goals of the group change. In other words, there is no consideration of the dynamics of leadership. 
In the post-war decades, social psychology focused on group dynamics and attitude change. A consensus emerged (still orthodox in textbooks) about the processes of social influence and persuasion. In these formulations it became assumed that conformity to and/or being persuaded by the group was a function of various kinds of dependence on the group (for approval, rewards, avoiding rejection, information, reducing uncertainty) to satisfy various kinds of personal needs. Leaders were implicitly understood as those upon whom others were dependent because they provided, or could provide, rewards. Gradually, then, leadership came to be seen as a form of psychological or social exchange in which, in return for the rewards provided by leaders, group members agreed to follow leaders thereby conferring respect, obedience and admiration (for example, Hollander 1958; French and Raven 1960). This transactional analysis focussed more on the leadership process than the particularities of the leader but still harked back to the person-centred view since it implied a process in which influence flows from specific capacities and personality of the leader which make him or her relatively less dependent on the group than vice versa. Influence flows from the less to the more dependent, but why some people are less dependent is never explored.

One response to the implausibility of the notion that we follow leaders on the basis of a careful, step-by-step, calculation of personal self-interest has been the reinvention of charismatic or transformational leadership (for example, Burns 1978; Bass 1990). Basically, where leaders are able to engender a sense of common purpose appealing to higher ideals and values, highlight the importance of the group's function and show concern for group members, positive outcomes are anticipated. These are themes that are familiar in management, political science, and organisational psychology but that, to some extent, re-describe certain forms of leadership rather than explain them. To the degree that transformational leaders are successful, it is not at all clear why this is so. There is discussion of leaders modelling behaviour, of fostering connections with the group and engaging members with the broader goals of the group, shifting and aligning personal self-interest with more collective interests. One of the issues is that the underlying processes at work have remained vague and unspecified, with the research literature being dominated by work on the constructs themselves (for example, how exactly is a transactional leader different from a transformational one? Are these leadership qualities mutually exclusive?), and confirming the validity and reliability of measurement tools. There is, however, a further move away from the personality view with a stronger emphasis on the fact that these leadership qualities can be acquired through experience, training and practice.

In the 1980s a new view of leadership began life, one still being developed. The central thesis is that leadership is a group process and depends on the existence of a shared social identity between the leader and other group members. This 
view offers an explanation of the underlying psychological processes that make leadership possible.

\section{The new view of leadership: self-categorisation and the psychological group}

What is the psychological basis of group membership? What leads a collection of individuals to perceive, feel, think and act as a group, in a collective, unitary manner pursuing common interests and goals? How does one rather than another of our group memberships become psychologically important or salient in a situation and affect behaviour? Which group member is likely to have most influence in the group? Self-categorisation theory (Turner et al. 1987), building on the insights from social identity theory (Tajfel and Turner 1979), provided a new set of answers to these questions and leads to a new view of leadership.

A central insight is that people can define themselves as individuals (' $\mathrm{I}$ ' and 'me') and as group members ('we' and 'us'). Personal identity or the personal self is used to describe situations where individuals perceive themselves to be distinct and different from others and social identity or the social self refers to an individual's knowledge of belonging to a certain group that has some psychological significance to that individual. Within this approach the term 'group', then, does not refer to demographic, sociological or role groups (for example, women, those with low socio-economic status, or politicians). The term refers to psychological groups where an individual defines him- or herself as being a member because the group is self-relevant and self-defining. The group membership is psychologically or subjectively significant for members in that it shapes how they define and evaluate themselves, provides norms and values, and directly affects how they behave in specific situations when it is salient.

When people self-categorise or identify with a particular ingroup, the norms, values and beliefs that define the group are internalised and influence the attitudes and behaviour of group members. Social identity involves a process of depersonalisation where the self comes to be perceived as interchangeable with other ingroup members (Turner 1982; 1985). So, it is argued that when social identity is psychologically operative or salient, individuals come to see other ingroup members as part of the self (redefining the self as 'we' rather than ' $\mathrm{I}$ '). It proposes that it is where people shift from defining themselves at the level of their personal identities to categorising themselves at the level of shared social identity that group behaviour becomes possible. Group behaviour as opposed to individual or interpersonal behaviour is simply people acting in terms of a shared social identity rather than differing personal identities.

It is important to note that, at this point in the history of social psychology, the impact of the original group dynamics tradition had worn thin and the very idea of a psychological group process which actively transformed people's 
relationships to each other had gone missing. Self-categorisation theory reinstated this notion, arguing that shared social identity qualitatively changed the nature of people's relationships with each other, producing a distinctive psychology and making possible new kinds of group processes (of, for example, mutual attraction, cooperation and influence).

The idea that the self is multi-levelled, including the personal self and the social self, is central to the SCT analysis and explains how one's group memberships (for example, as Australians, conservatives, Catholics) can come to impact on the individual psychology of the person. It is possible to define oneself as an individual, as a member of particular groups in contrast to others and as a member of higher-order more inclusive 'ingroups'. At different times in different situations we define 'who we are' in different ways. Defining the self at a more inclusive level in term of some social category' in contrast to some other category, creates psychological interchangeability and can transform those who may be competitors and antagonists at one level (as individuals or sub-group members) to allies and as part of 'us' at another. The emergence of new identities and new ways of defining oneself can also affect lower-level identities. What it means to be a member of the Liberal versus the Labor party at a particular time, under a particular leadership, will affect the meaning of particular sub-groups within the parties (for example, what it means to be more left or right) and individual members attitudes towards certain issues and policies. One's higher-level self-categorisations as a party member may affect lower-level beliefs, values and opinions such as an individual's attitudes to various social and economic issues.

When there is a shared social identity there is a motivation to act in ways that advance the group's collective interests and goals and to ensure that one's own ingroup is positively distinct from other (out)groups. There are also greater opportunities for mutual influence and persuasion with the ingroup. Because other ingroup members are viewed as similar to oneself, they become a valid source of information and a testing ground for one's own views on relevant dimensions.

A shared social identity leads people to agree and to expect to agree where they confront a shared stimulus reality or object of judgement, and a consensual response to some identical situation subjectively validates the response as correct, right, appropriate and/or demanded by the objective situation (Turner 1987; 1991). Within any group it is the degree to which any response expresses the ingroup consensus or norm in relation to a stimulus that makes it persuasive, that defines it as likely to be true, valid, right and so on. Thus, within any group that shares a salient relevant identity, responses will differ in the degree to which they express, embody or represent that consensus and individuals will differ in the degree to which they embody that identity. 
Relative influence within a psychological group reflects and is driven by these gradients of relative prototypicality (to use the term taken from self-categorisation theory to define the degree to which any member of a category is more or less defining of the category as a whole). Relative prototypicality is not given by closeness to the average judgement, but by a new theoretical principle which is assumed to apply to all categorising, the principle of meta-contrast. We seek to ensure that the differences perceived between categories are larger than the difference perceived within categories. Any group member is more prototypical to the degree that he or she differs more from outgroup members and less from ingroup members (for example, Hogg, Turner and Davidson 1990). Forgetting the technicalities, meta-contrast turns out to be fundamental because it tells us that identity is contrastive, flexible and relational. We are defined as much by what we are not as by what we are and the definition of both varies with the psychological and social context within which it is made.

There is no doubt that people have multiple ways of self-categorising available to them and are members of multiple, sometimes conflicting groups. Existing identities can shape the way new identities emerge and are created and new identities in some ways must serve to realign existing (potentially conflictual) identities and their meaning. A crucial idea is that self-categories vary in terms of level of inclusiveness, kind, defining dimensions (content or meaning) and internal structure (the relative prototypicality of instances/category members). All of these vary as different self-categories are created and become salient. In this way, self-categorising is assumed to be highly reality-oriented, dynamic and variable, but always tied to people's motives and goals, experience, knowledge and theories about the world. These are assumed to be interactive, not additive, factors in producing salient self-categories.

Thus far we are dealing with basic processes. Leadership is conceptualised as relative influence and power within a group where leaders are perceived as relatively more prototypical than others and hence more influential. People follow leaders because they embody ' $u$ s', and define what 'we' think is true and right, and do a better job than the rest of us of expressing what 'we' have in common. Often there are differences in roles, responsibilities, expertise, knowledge, and so on within a group (for example, a team, an organisation, an institution). What matters in relation to leadership and influence is whether or not these asymmetries are accepted as being legitimate and appropriate (i.e., the role of elites as leaders in a democratic system; see Kane and Patapan, this volume). To put these ideas to work in the context of all the many complexities of concrete life, it is useful to make some elaborations. 


\section{Leadership is not a product of personal factors but a group process}

In self-categorisation theory, leadership does not flow from fixed, stable qualities of the individual, but from a person's perceived position within the nexus of intra-group and intergroup relations that define the identity of the group. Relative prototypicality and leadership are group properties of a person which change with the nature of the group as a whole and how it defines itself, as well as how a group defines itself varies (interacting with other things) with the context within which it is defined. Group identity is not defined simply by intra-group similarities, but by the meta-contrast between how we differ from each other compared to how we differ from them. A powerful illustration on which research has been done is group polarisation, showing how extremists within a group can gain or lose influence as a function of the outgroup, against which the ingroup defines itself. When thinking about a faction within the Labor party, the influence of this group over the views of more moderate party members will be affected by the comparative context. At a national party meeting, internal ingroup and outgroup divisions are likely to emerge within the Labor party itself (for example, left-wing extremists versus moderates). When the focus is on comparisons between the Labor party and the conservatives, however, the previous internal 'outgroup' will be re-defined as more 'ingroup' and become more prototypical, increasing opportunities for influence (for example, David and Turner 2001).

Leadership is distributed in that all psychological group members are perceived as more or less prototypical and exert more or less influence and all, even the least influential, contribute to the definition of the group as a whole. There is no strong absolute divide between leaders and followers in terms of some leadership 'essence'. At a given time a given group will define itself in light of its needs, goals, experience, situation, knowledge, ideology and other groups. Its identity will take on the special meaning derived from that interplay of perceiver factors and reality, and the member, role or subgroup which best embodies that identity by virtue of whatever factors and for whatever reason will acquire the force of credibility, the mantle of authority and the aura of power. As individuals or subgroups seek to shape, control, reinvent and define group identity ('who we are') in light of events, or fail to do these things, leadership may remain stable or change. Leadership being a group process means that changes in leadership depend on changes in group identity. This analysis offers a view of contingency that is more complex than previously believed and recognises the relationship between leaders and other group members in a broader context of individual and group dynamics.

Naturally, leaders have special qualities. All human beings have special qualities, but there is no one set of special qualities which ensure that one will be, become, 
or stay a leader. What matters for any particular set of personal factors to become leadership factors is that the group follows, is persuaded and sees those factors as being embodied in itself. There are individual factors, but they exert influence only insofar as they are seen at any time, by any given group, as representing its identity better than others do.

There is no question that leaders actively seek to embody, control and manipulate identity in order to maintain their place in the sun. Some leaders are 'identity entrepreneurs' who, through engaging in argumentation and political rhetoric, seek to maintain their relative prototypicality and their position (for example, Reicher and Hopkins 2001). Along these lines, work on political leadership in the UK has examined the ways in which politicians have canvassed the critical Scottish vote by trying to embody values that are deeply rooted in that group's history. Politicians attempt to portray themselves as being 'typically Scottish' and invoke this identity in their political communication. All leaders claim equally to represent Scotland but very different ideas of 'Scottishness' are crafted to suit the leader's and the party's policy platform (for example, Reicher, Drury, Hopkins and Stott 2001).

There is also evidence that leaders can attempt to restructure the social context and the definition of the group in ways that make their position more prototypical. Seeking conflict with an outgroup is one such response. A series of studies by Rabbie and Bekkers (1978) indicated that when the position of leaders becomes unstable they are more likely to engage in intergroup conflict rather than avoid it. It could be argued, for example, that the Tampa affair in 2001 was very much about what it meant to be 'Australian' and about Prime Minister John Howard as being best placed to lead such a nation (Marr and Wilkinson 2004). Thus, understanding leadership as a group process does not deny the capacity of leaders to make use of their insights into that process, conscious or otherwise.

Leadership is as much about being able to reflect and embody the group, as being able to create and shape 'who we are' in ways that are meaningful to the group. Conflict with an outgroup or minority can be used directly to create and or reshape ingroup identity and hence make oneself more representative of the ingroup and legitimate. The same is true when one demonises and discriminates against a minority group. Prejudice against a minority can be used to reshape the mainstream identity, place oneself at the core and increase one's power (Subasic, Turner and Reynolds 2007). Leading up to World War II, the Nazi portrayal of Jews as dangerous, shrewd, and evil was used not only to justify this group's harsh treatment, but also served to define a particular version of the national identity (i.e., what it meant to be German) in a way that most effectively mobilised support for the Nazi Party. 
The point is that leadership is much more conferred than imposed. It flows from the nature of the group rather than the nature of the person leading and it is an outcome of group identity rather than being linked to the pre-ordained life trajectory of any one individual (for example, Turner 1991; Turner and Haslam 2001; Haslam 2004; Reicher, Haslam and Hopkins 2005). It is through defining 'who we are' that leader's are able to influence 'what we do'. Leadership stability or variability is tied to whether group identity varies or is stable. The universality of leadership derives from the social and psychological character of human groups.

\section{Influence versus power: beyond leadership as resource control}

So far we have talked of leadership in terms of influence - meaning persuasion - but what of power? Surely power based on authority and coercion can override influence? Can leaders with power ignore, suppress or deny the influences which flow from identity? To a degree certainly, but the new view underlines the limitations of force without legitimacy and authority without identification (Turner 2005). In the old view, power is the capacity to influence, to produce intended effects in others' attitudes and behaviours, based on various kinds of resources (capacities to provide positive and negative outcomes). This view draws on the most general way of understanding power, as the capacity to cause or have effects on things and people, but we think it is highly misleading as a conception of social power. It confuses power over people (a kind of social domination) with power through people. The theory of power which flows from self-categorisation theory argues that social power is the capacity to have effects on people and things through people, through being able to rely on, or get others to carry out one's will. Being able to stop somebody by shooting him or her is certainly power to have an effect, but social power is where one can get others to carry out the order. Social power also is being able to stop someone through influence and persuasion rather than coercion - through ideas rather than force.

There are three processes of power in the new view - persuasion, authority and coercion - and all three rest directly or indirectly on identity and the influence processes which flow from it. Persuasion directly reflects shared social identity, authority is leadership legitimated by ingroup norms, values and structure and the coercion of people against their will requires that there be coercive agents over whom the leader has influence and authority. Persuasion, authority and coercion flow from leaders, elites, institutions and authorities acting in line with the rules, laws, principles and beliefs that 'we are supposed to share'. Unlike in the traditional model of power, where control of resources leads to power and power leads to influence, this theory argues that group identity leads to influence, which in turn is the foundation of power (redefined as getting others to carry out one's will). Social power flows from group identity, organisation and ideology 
in this conception much more than from the control of resources desired by others. The implications of the two views are starkly different, as here we can only begin to explore.

The idea that 'resource control' is the basis of power tends to imply that differences in power between individuals and groups are relatively static and enduring. So long as one controls sufficient resources, it seems, one has power and those without resources have little option but to submit. It is difficult to see how power ever changes hands in this view. In practice there are many examples from real life of relatively rapid gains and losses in power where individuals and groups without initial resources become more powerful and those with overwhelming resources suddenly lose power. Turner (2005) gives an example of the New Model Army in the English Civil War that was created as a resource for the parliamentarians to oppose King Charles but then the resource itself turned on Parliament with certain factions taking control (Fraser 1997).

The new view of the dynamics of leadership outlined here makes sense in this context since it assumes that power reflects group identity and that all self-categorising is relational and dynamic, varying with social comparisons within and between groups, the specific social context, and the collective goals, values and beliefs of group members. Thus, for example, as intergroup relations change, so that cooperation between groups is replaced by conflict, then group identity is likely to polarise to emphasise differences from the conflicting outgroup and more extreme, conflictual members will tend to become more prototypical of each group than will more moderate members. Thus the more extreme members will gain in influence and authority over moderates. Stott, Adang, Livingstone and Shreiber (2007) have demonstrated the workings of these dynamics in the context of the policing of crowds and soccer hooliganism amongst English fans. Police actions that fail to recognise the differences between hooligans and more moderate fans (i.e., their use of coercive force in an indiscriminate way) serves to create an oppositional identity where resistance, conflict and violence against the police comes to be viewed as legitimate. As a function of police treatment the 'moderate' fan identity changes, so that they become empowered to resist the police and move more towards the position of the hooligans in opposition to the police. The emergence of such a confrontational 'English fan' identity may serve to recreate and escalate such conflict in future social contexts.

The idea of coercion by leaders evokes an image of control which cannot be resisted because it is based on overwhelming force. Far from being impossible to resist, however, coercion is often dangerously counter-productive. The coercion of a target tends to increase social distance from and dis-identification with the leader, undermines trust and feelings of control, and induces private rejection of the influence attempt. These are the kernels from which resistance 
and bloody-mindedness can grow with the goal of rejecting control and restoring freedom of action. Coercion persisted in, without the cloak of legitimacy, tends to produce private attitude change away from the leader, reactance, conflict and the emergence of a countervailing force. Authority is also undermined where a 'fifth column' sympathises with the enemy or where the conflict creates an ingroup identity in contrast, which marginalises the established leadership. Conflict and force therefore by no means necessarily strengthen established leadership, but it is still true that conflict can be used for such ends.

Is coercion always bad? No. Selective coercion can certainly be useful if the aim is to destroy, impede or constrain an enemy, but this is conflict rather than leadership through influence, and prevents the likelihood of influence in the future. The danger is that people assume that coercion provides a form of influence like any other. They ignore the fact that it undermines shared identity and so produces the very opposite of what they intended. Coercion, like all conflict, redefines identity and hence has direct implications for the power of leaders, but not necessarily as intended.

The implication is that power differences in society are constantly shifting and that power change is as normal as stability. The power of leaders and groups depends on identity, organisation and ideology and these foundations are always being built up or torn down, being developed creatively or deteriorating in indifference, as a function of partisan interests, collective experience, new tasks and problems and the endless battle between belief and reality. The power of leaders will rise or fall with any factor which makes them more or less representative of ingroup identity and authority. Changes in the collective goals, beliefs, attitudes, circumstances and even mood of the group, in fact any factor which leads the ingroup to define itself and its collective interests differently, can have implications for which members will have influence and power irrespective of the resources they control. A factor in radical change is often that some subordinate group develops a distinct identity through which to develop its own goals, values and beliefs, contest the power of the dominant group and reject as illegitimate the authority of the social order. Apart from what makes leaders, there is also the issue of how leaders lose or destroy their own authority and what damage is done as they seek to survive.

\section{Conclusion: public leadership and organisational effectiveness}

In sum, self-categorisation theory does not see power as fundamentally oppressive, divisive or tending to corruption. On the contrary, leadership is valuable and necessary. For a group to pursue its collective will there must be a power structure through which group identity and goals are realised. Organisations must solve the problems of power to function effectively since without effective leadership there cannot be unified, coordinated, cooperative 
action towards a common goal by large masses of people. Good leaders give people power rather than take it away, the power to pursue collective goals. Power flows to leaders who authentically embody the collective self. It is a free process, reflecting people's understanding of themselves and the world.

It is also true that authority can degenerate into coercion and lead to abuse. Authority provides the opportunity and temptation for reliance on coercion and at the same time may under certain conditions encourage those in authority to differentiate themselves from followers and develop partisan, separate interests. It is easy to see how the nature of coercion is likely to brutalise the authority that wields it and produce a cycle of conflict and even violence in which mutual hatred, delegitimation and self-justification thrive. It is also easy to see how a leader who has developed interests which conflict with those of subordinates will engage in deception, manipulation, coercion and terror to maintain his or her position, since by definition there can be no appeal to the common good other than dishonestly (for example, Pinochet's National Plebiscite of 1980). A leader may well believe their agenda for change is for the good of all and that time will vindicate their own and their supporters' actions. A failure to influence others about the future and that such trust is well placed, is an indicator of leadership failure.

Learning how to remove failed leaders efficiently is a problem that organisations and communities must solve to function effectively. Ineffective leaders do not merely fail to realise potential, they can be destructive as they seek to create an identity, culture and organisation, factions and divisions, which enable them to survive. We talk rarely of the huge damage done to organisations and institutions by leaders who are unable to meaningfully align identities and interests in ways that are of benefit to the group as a whole, in part because of our fixation on leadership as a set of personal traits.

The present view suggests a focus on organisational effectiveness in relation to the functioning of power structures might be timely. Education, transparency, and engagement need to be encouraged. The group having access to information that can be used to decide in whose interests certain decisions are being made is critical (for example, freedom of information, free media, a balanced judiciary, establishing, communicating and validating principles and procedures for decision-making). There has been little consideration of the ways to ensure leaders are judged in relation to the shared identity, aims and values and can be removed speedily where they fail to function as the group intended.

There is a challenge for those that at some level recognise the power of groups and are familiar with an analysis of group-based and constituent interests (for example, in the world of politics and public administration) to cease to perpetuate the person-centred view of leadership. There is a need to consider the dynamics of leadership and the way structures, conventions, policies, and values can 
create, shape, redefine, and modify identities, and the implications for leadership. These points speak to the heart of leadership as a group process and serve to locate public leadership not as being over the public or done to the public, but for and through the public.

\section{References}

Bass, B. M., 1990, 'Power and Leadership', Bass \& Stogdill's Handbook of Leadership: Theory, Research, and Managerial Applications, $3^{\text {rd }}$ ed., New York: The Free Press, pp. 225-73.

Burns, J. M., 1978, Leadership, New York: Harper \& Row.

David, B. and J. C. Turner, 2001, 'Self-categorization principles underlying majority and minority influence', in J. P. Forgas and K. D. Williams (eds), Social influence: Direct and Indirect Processes, Philadelphia, PA: Psychology Press.

Fielder, F. E., 1964, 'A contingency model of leader effectiveness', in L. Berkowitz (ed.), Advances in Experimental Social Psychology, Volume 1, New York: Academic Press, pp. 149-90.

Fraser, A., 1997, Cromwell: Our Chief of Men, London: Arrow Books.

French, J. P. R. Jr., and B. Raven, 1960, 'The bases of social power' in D. Cartwright and A. Zander (eds), Group Dynamics, New York: Harper and Row, pp. 607-23.

Haslam, S. A., 2004, Psychology in Organizations: The Social Identity Approach, 2nd ed., London: Sage.

Hogg, M. A., J. C. Turner and B. Davidson, 1990, ‘Polarised norms and social frames of reference: A tests of self-categorization theory of group polarisation', Basic and Applied Social Psychology, 11, pp. 77-100.

Hollander, E. P., 1958, 'Conformity, status, and idiosyncrasy credits', Psychological Review, 65, pp. 117-27.

Lewin, K., R. Lippett and R. White, 1939, 'Patterns of aggressive behaviour in experimentally created "social climates",' Journal of Social Psychology, 10, pp. 271-99.

Marr, D. and M. Wilkinson, 2004, Dark Victory, Crows Nest: Allen and Unwin.

Mann, R. D., 1959, 'A review of the relationship between personality and performance in small groups', Psychological Bulletin, 56, pp. 241-70.

Rabbie, J. M. and F. Bekkers, 1978, 'Threatened leadership and intergroup competition', European Journal of Social Psychology, 8, pp. 9-20.

Reicher, S. D. and N. Hopkins, 2001, Self and Nation: Categorization, contestation and mobilisation, London: Sage. 
Reicher, S. D., J. Drury, N. Hopkins and C. Stott, 2001, 'A model of crowd prototypes and crowd leadership', in C. Barker, M. Lavaletee, and A. Johnson (eds), Leadership and Social Movements, Manchester: Manchester University Press.

Reicher, S., S. Haslam and N. Hopkins, 2005, 'Social identity and the dynamics of leadership: Leaders and followers as collaborative agents in the transformation of social reality', Leadership Quarterly, 16:4, pp. 547-68.

Reynolds, K. J., and J. C. Turner, 2006, 'Individuality and the prejudiced personality', European Review of Social Psychology, 17, pp. 233-70.

Simon, B. and B. Klandermans, 2001, 'Politicized collective identity: A social psychological analysis', American Psychologist, 56, pp. 319-31.

Stott, C. J., O. M. Adang, A. Livingstone and M. Shreiber, 2007, 'Variability in the collective behaviour of England fans at Euro2004: public order policing, social identity, intergroup dynamics and social change', European Journal of Social Psychology, 37, pp. 75-100.

Subasic, E., J. C. Turner and K. J. Reynolds, 2008, Creating a minority to create a shared identity: Dynamics of inclusion/exclusion and subordinate support for legitimate authorities, Manuscript in preparation, The Australian National University.

Tajfel, H. and J. C. Turner, 1979, 'An integrative theory of intergroup conflict', in W. G. Austin and S. Worchel (eds), The Social Psychology of Intergroup Relations, Monterey, CA: Brooks/Cole, pp. 33-47.

Turner, J. C., 1982, 'Towards a cognitive redefinition of the social group', in H. Tajfel (ed.), Social Identity and Intergroup Relations, Cambridge, England: Cambridge University Press; Paris: Éditions de la Maison des Sciences de l'Homme, pp. 15-40.

Turner, J. C., 1985, 'Social categorization and the self-concept: A social cognitive theory of group behaviour', Advances in Group Processes, 2, pp. 77-122.

Turner, J. C., 1987, 'The analysis of social influence', in J. C. Turner, M. A. Hogg, P. J. Oakes, S. D. Reicher, and M. S. Wetherell, Rediscovering the Social Group: A Self-Categorization Theory, Oxford: Blackwell.

Turner, J. C., 1991, Social Influence, Milton Keynes, UK: Open University Press.

Turner, J. C., 2005, 'Explaining the nature of power: A three-process theory', European Journal of Social Psychology, 35, pp. 1-22.

Turner, J. C., M. A. Hogg, P. J. Oakes, S. D. Reicher and M. S. Wetherell, 1987, Rediscovering the Social Group: A Self-Categorization Theory. Oxford and New York: Basil Blackwell. 
Turner, J. C., P. J. Oakes, S. A. Haslam and C. McGarty, 1994, 'Self and collective: Cognition and social context', Personality and Social Psychology Bulletin, 20, pp. 454-63.

Turner, J. C., and P. J. Oakes, 1997, 'The socially structured mind', in C. McGarty and S. A. Haslam (eds), The Message of Social Psychology: Perspectives on Mind in Society, Malden, US: Blackwell Publishing, pp. 355-73.

Turner, J. C. and S. A. Haslam, 2001, 'Social identity, organizations and leadership', in M. E. Turner (ed.), Groups at Work. Advances in Theory and Research, Hillsdale, NJ: Erlbaum, pp. 25-65.

Turner, J. C., K. J. Reynolds, S. A. Haslam, and K. J. Veenstra, 2006, 'Reconceptualizing personality: Producing individuality through defining the personal self', in T. Postmes and J. Jetten (eds), Individuality and the Group: Advances in Social Identity, London: Sage, pp. 1-36.

\section{ENDNOTES}

1 This research was supported by an Australian Research Council grant. We would like to thank Professor Paul 't Hart and Professor John Uhr, as well as the participants in the public leadership forum and Dr Chris Beer for helpful comments on this chapter. 